\title{
Internal environment for growth of cancer cells in mice: hypothermia, anemia and lymphocytopenia
}

\author{
Mayumi Watanabe ${ }^{1}$, Hiroaki Matsumoto ${ }^{1}$, Chikako Tomiyama $^{2}$, Kohei Akazawa $^{3}$, Toru Abo $^{1 *}$ \\ ${ }^{1}$ Department of Immunology, Niigata University School of Medicine, Niigata, Japan; \\ *Corresponding author: immunol2@med.niigata-u.ac.jp \\ ${ }^{2}$ School of Health Sciences, Faculty of Medicine, Niigata University, Niigata, Japan; \\ ${ }^{3}$ Department of Medical Informatics, Niigata University Medical \& Dental Hospital, Niigata, Japan
}

Received 14 February 2011; revised 15 March 2011; accepted 5 April 2011.

\begin{abstract}
The internal environment in tumor-bearing mice was investigated in detail. When EL-4 lymphoma cells $\left(5 \times 10^{6}\right.$ cells/mouse) were intraperitoneally inoculated into C57BL/6 mice, approximately $70 \%$ of the mice died by day 24 . In this regard, the internal environment was compared between control mice, surviving mice and tumor-bearing mice which died. The most prominent sign was hypothermia $\left(<34^{\circ} \mathrm{C}\right.$ from day 16$)$ seen in tumor-bearing mice which died. Control mice and surviving mice did not show such hypothermia (around $38^{\circ} \mathrm{C}$ ). Other changes, including anemia and lymphocytopenia, were also seen in tumor-bearing mice which died, but not in control mice and surviving mice. Immunological study revealed that NKT cells, which have been previously identified to be the major effector lymphocytes against EL-4 cells, almost disappeared, especially in the liver of tumor-bearing mice which died. These results suggest that a specific internal environment might be required for continuous tumor growth in vivo. Such internal environmental factors include hypothermia, anemia and severe immunosuppression.
\end{abstract}

Keywords: Cancer; Hypothermia; Anemia; Immunosuppression; Glycolysis; Mitochondria

\section{INTRODUCTION}

Many clinicians have noticed that cancer patients have anemia and immunosuppression, especially those in their advanced stage [1-7]. One hypothesis is that such conditions are the results from cachexia in cancer patients [8-12]. Cachexia is known to be mediated by $\mathrm{TNF} \alpha$, $\operatorname{TGF} \beta$, etc., and these responses are common phenomena seen in patients with advanced cancer.
In a recent study, it was demonstrated that cancer patients even in their early stage suffered from hypothermia, anemia and immunosuppression [13]. This raised the possibility that these internal conditions might be essential for the onset of cancer and the maintenance of cancer cell growth. Cancer cells carry few mitochondria in the cytoplasm and their major energy production is supported by glycolysis [14-16]. To maintain the glycolysis pathway, hypothermia and anemia (hypoxia) are required.

In light of these findings, the object of this research is to investigate whether a similar internal environment is seen in tumor-bearing mice. Under the present applied protocol using EL-4 lymphoma cells [17,18], approximately $70 \%$ of the mice inoculated with EL-4 cells died of cancer while the remaining $30 \%$ of the mice survived irrespective of the inoculation. Therefore, the data were analyzed between three groups, i.e., control mice, surviving mice and tumor-bearing mice which died. As a result, only tumor-bearing mice which died consistently showed hypothermia, anemia and immunosuppression.

\section{MATERIALS AND METHODS}

\subsection{Mice}

C57BL/6 (B6) mice [19] were purchased from Clea Japan (Tokyo, Japan). All mice were used at 6-8 weeks of age in these experiments. These mice were fed under specific pathogen-free conditions in the animal facility of Niigata University (Niigata, Japan).

\subsection{Tumor Inoculation}

EL-4 lymphoma cells $\left(5 \times 10^{6}\right.$ cells/mouse $)$ were injected into mice intraperitoneally (i.p.) $[17,18]$. This cell line is of B6 background. At day 16 after tumor inoculation, their liver, spleen, thymus and bone marrow (BM) were harvested. 


\subsection{Cell Preparation}

Mice anaesthetized with ether were sacrificed by exsanguination from the subclavian artery and vein, and various organs were removed. Hepatic lymphocytes were prepared as previously described [20]. Briefly, the liver was pressed through 200-gauge stainless steel mesh and suspended in Eagle's MEM medium supplemented with $5 \mathrm{mM}$ Hepes (Nissui Pharmaceutical, Tokyo, Japan) and $2 \%$ FCS. After one washing, the pellet was resuspended in $35 \%$ Percoll solution containing $100 \mathrm{U} / \mathrm{ml}$ heparin and centrifuged at $2000 \mathrm{rpm}$ for $15 \mathrm{~min}$. The pellet was resuspended in red blood cell (RBC) lysis solution $\left(155 \mathrm{mM} \mathrm{NH}_{4} \mathrm{Cl}, 10 \mathrm{mM} \mathrm{KHCO}{ }_{3}, 1 \mathrm{mM}\right.$ EDTA, $170 \mathrm{mM}$ Tris, $\mathrm{pH}$ 7.3) and then washed twice with the medium. Splenocytes and thymocytes were obtained by forcing the spleen and thymus, respectively, through stainless steel mesh. BM cells were obtained by flushing femurs with medium. Splenocytes and BM cells were treated with $0.2 \% \mathrm{NaCl}$ solution to remove RBC.

\subsection{Measurement of Body Temperature (Rectal Temperature), Glucose, Lactate and $\beta$-ketone}

Body temperature (rectal temperature) was determined by using THERMAC SENSOR (Shibaura Denki Co., Tokyo). Blood glucose and $\beta$-ketone were measured by Precision Xtra (TM) (Abbott Japan Co., Ltd., Chiba, Japan). Urine glucose level was checked by Bayer KetoDiastix urine checker (Siemens Healthcare Diagnostics, UK). To analyze the hematological parameters, the numbers of leukocytes and erythrocytes (RBC) in the blood were determined by hemocytemeter. Granulocytes, lymphocytes and monocytes were determined by Giemsa staining.

\subsection{Flow Cytometric Analysis}

The phenotype of cells was identified by two-color immunofluorescence tests [20]. The reagents used here included anti-CD3 $\varepsilon$ (145-2C11), anti-IL-2R $\beta$ (TM $\beta-1)$, and anti-NK1.1 (PK136) mAbs (PharMingen, San Diego, $\mathrm{CA})$. All $\mathrm{mAbs}$ were used in fluorescein isothiocyanate (FITC)-, phycocerythrin (PE)-forms. To prevent nonspecific binding of $\mathrm{mAb}$, anti-CD16/CD32 (2.4 G2) mAb was added before staining with labeled mAbs. The suspended cells $\left(5 \times 10^{5}-2 \times 10^{6} /\right.$ tube $)$ were stained with $\mathrm{mAbs}$ and stained cells were analyzed with a FACScan (Becton-Dickinson). Dead cells were excluded by forward scatter, side scatter, and propidium iodide gating.

\subsection{StatisticalAnalysis}

The difference between the values was determined by
ANOVA and a post-hoc test.

\section{RESULTS}

\subsection{Cancer Death and Hypothermia}

Tumor-bearing mice began to die around day 20 after the inoculation of cancer cells (Figure 1(a)). Up to day 24 , approximately $70 \%$ of the mice died. Since these results (i.e., $70 \%$ died and $30 \%$ survived) were consistently repeated, we separated the mice into two groups, i.e., those which died and those which survived. In comparison with control mice, the body weight of two tumor-bearing mice was almost comparable up to day 20 (Figure 1(b)). However, body temperatures of two groups were found to be different. From day 16, the group of mice which eventually died showed a decrease of body temperature. All mice which died suffered from hypothermia.

\subsection{Glucose in the Blood and Urine of Tumor-Bearing Mice}

In our previous human study [13], some cancer patients had hyperglycemia as well as hypothermia. We therefore examined whether a variation of blood glucose was also shown in tumor-bearing mice (Figure 2(a)). Control mice and mice which survived did not show any variation of blood glucose. In contrast, tumor-bearing mice which died finally showed a decreased level of blood glucose. This was due to the leakage of glucose into the urine (Figure 2(a), bottom). The levels of lactate and $\beta$-ketone were comparable between all tested groups (Figure 2(b)). There was a tendency that these levels were slightly high in tumor-bearing mice, especially in mice which died.

\subsection{Anemia and Lymphocytopenia in Tumor-Bearing Mice}

The number of RBC was enumerated in the blood of control and tumor-bearing mice (Figure 3(a)) From day 16 after tumor inoculation, anemia was seen in tumor-bearing mice. This was true in both tumor-bearing mice which died and those which survived. The number of WBC was also enumerated. However, there was not big difference among all tested mice. We then examined the ratios of leukocyte subsets, including granulocytes, lymphocytes and monocytes (Figure 3(b)). The most prominent change was seen in tumor-bearing mice which died. Namely, the ratios of granulocytes and monocytes increased and that of lymphocytes decreased from day 16. This pattern showed severe immunosuppression at the late stage in tumor-bearing mice which died. 


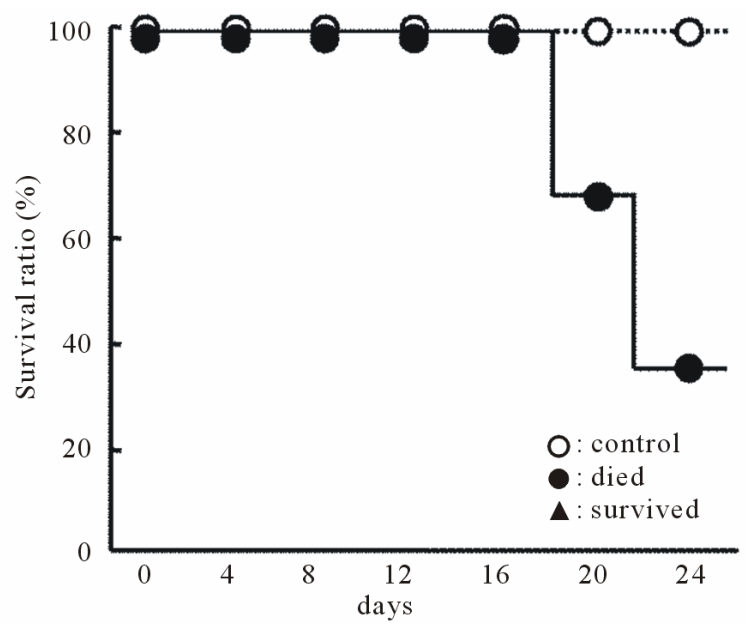

(a)
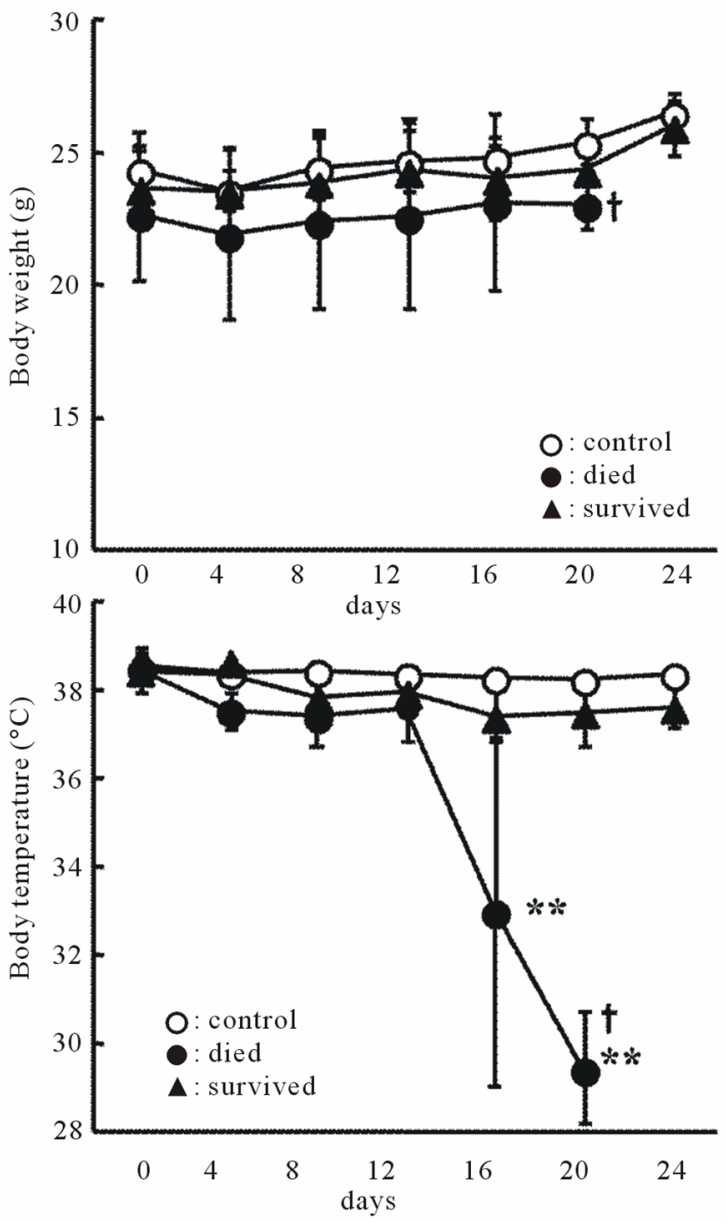

(b)

Figure 1. Time-kinetic study after tumor inoculation. (a). Survival ratio, (b). Body weight and body temperature (rectal temperature). Ten mice were used to determine survival ratio. The mean and one SD of body weight and body temperature were produced from 4 mice at each point of time. $\uparrow$ death $* * \mathrm{P}<0.01$.
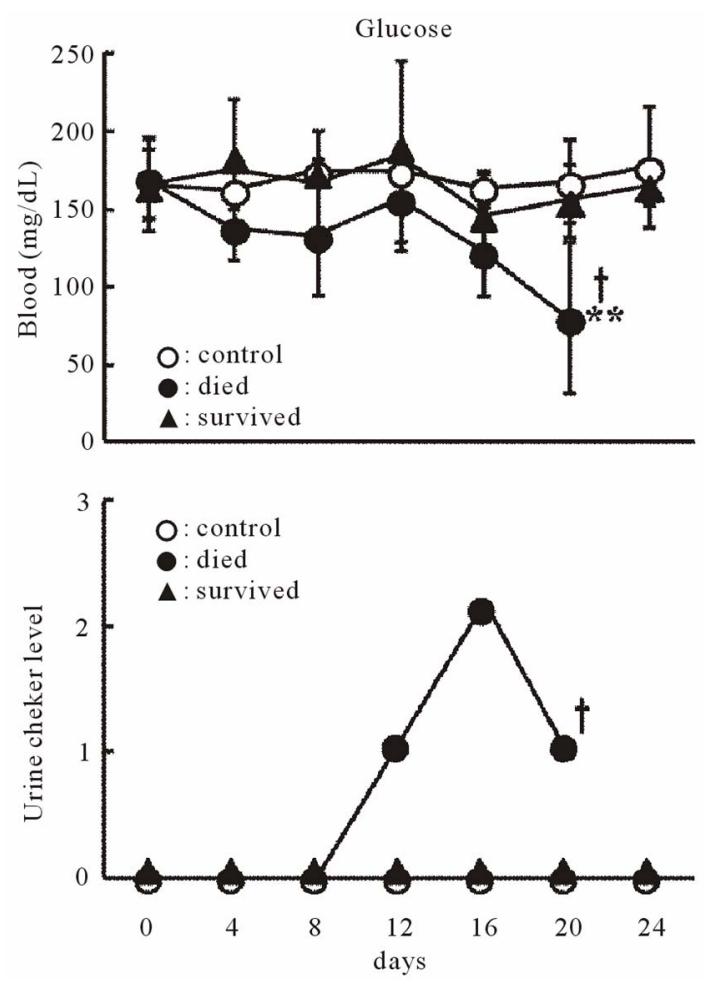

(a)
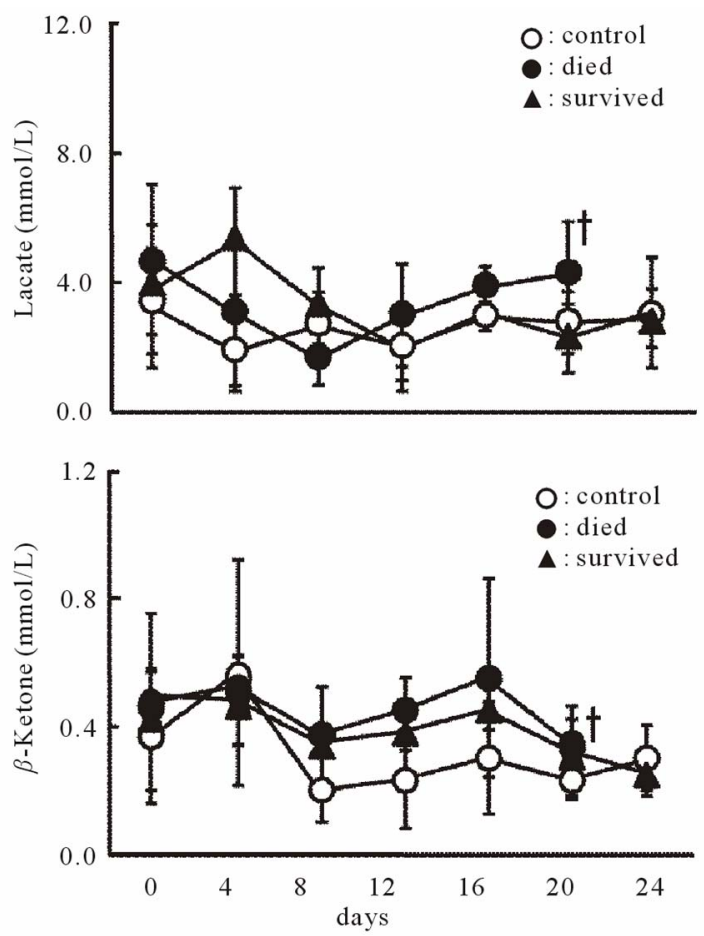

(b)

Figure 2 Parameters in the blood and urine. (a). Glucose in the blood and urine, (b). Lactate and $\beta$-ketone in the blood. The mean and one SD of parameters in the blood were produced from 4 mice at each point of time. $\uparrow$ death $* * \mathrm{P}<0.01$. 


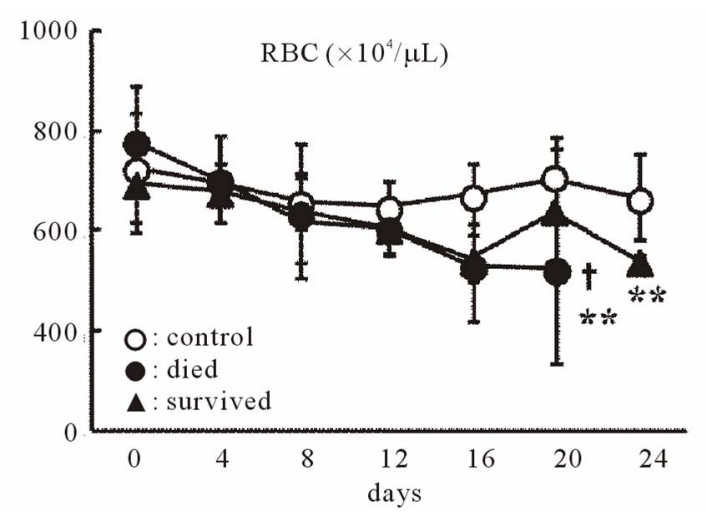

(a)
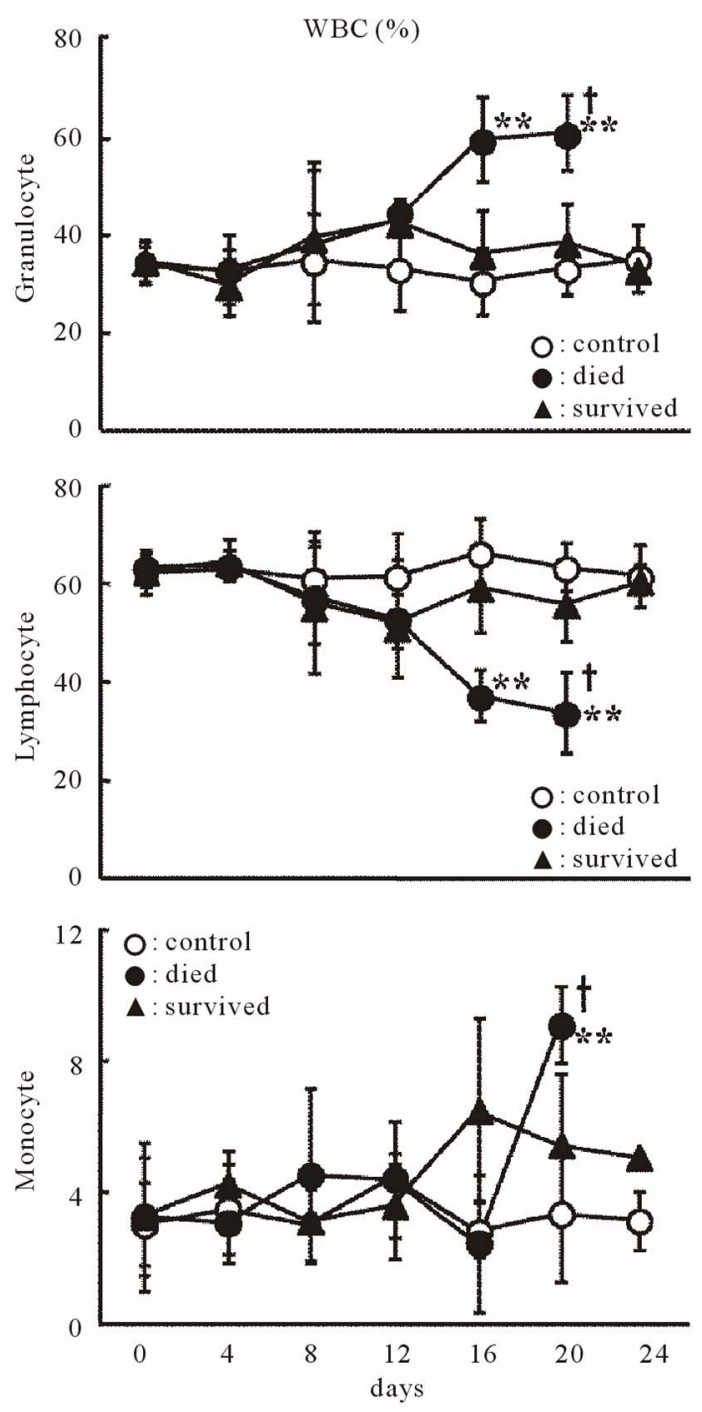

(b)

Figure 3. Number and proportion of cells in the blood. (a). The number of RBC, (b). The proportion of granulocytes, lymphocytes and monocytes. The mean and one $\mathrm{SD}$ of parameters in the blood were produced from 4 mice at each point of time. $\dagger$ death $* * \mathrm{P}<0.01$.

\subsection{Decrease in the Proportion of NKT Cells}

Which subsets of lymphocytes decreased in tumorbearing mice were examined (Figure 4). Two-color immunofluorescence tests were conducted to identify lymphocytes subsets. Lymphocytes were isolated from the liver, spleen and thymus on day 16 . Two-color staining for $\mathrm{CD} 3$ and IL-2R $\beta$ identified IL-2R $\beta^{+} \mathrm{CD} 3^{\text {int }}$ cells, whereas that for CD3 and NK1.1 identified NKT cells $\left(\mathrm{NK} 1.1^{+} \mathrm{CD} 3^{\text {int }}\right)$. The proportions of both $\mathrm{IL}-2 \mathrm{R} \beta^{+} \mathrm{CD} 3^{\text {int }}$ cells and NKT cells were found to decrease in the liver of tumor-bearing mice which died. Surviving tumorbearing mice did not show such a decrease.
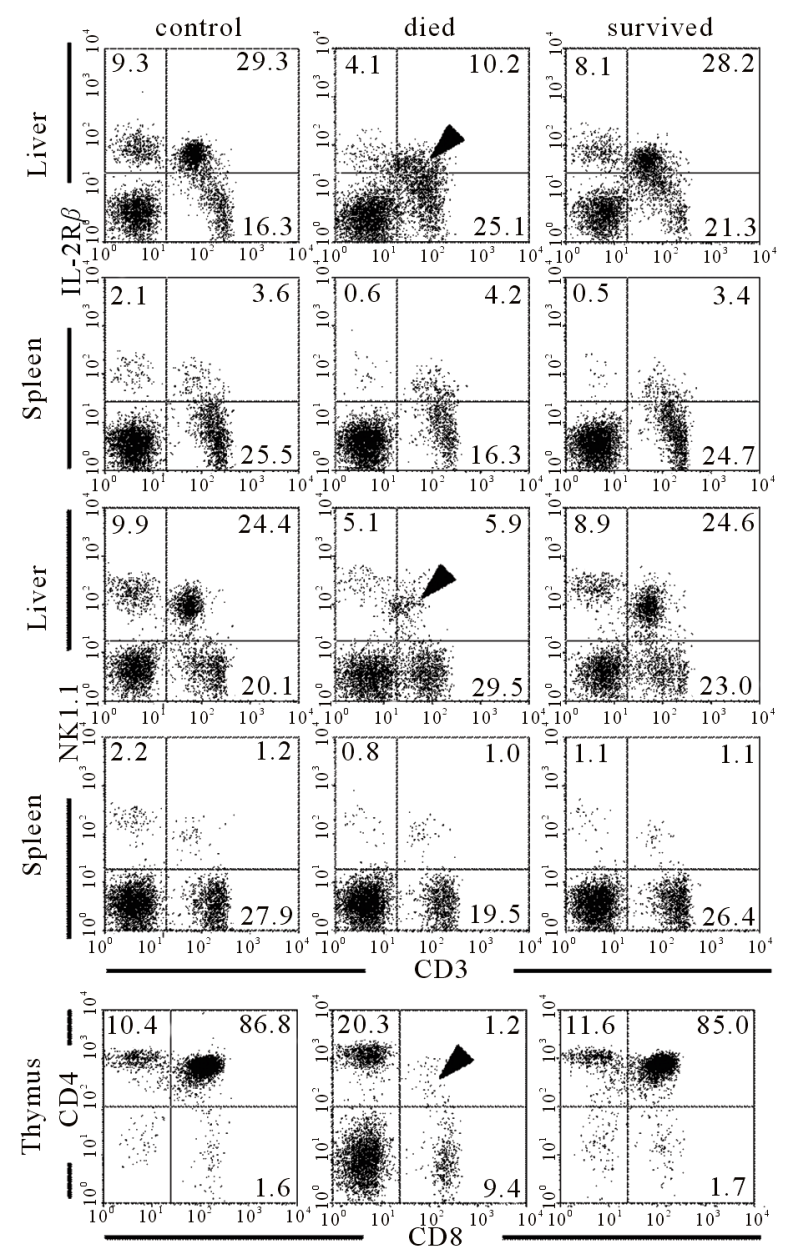

Figure 4. Immunofluorescence tests to identify lymphocyte subsets. Lymphocytes were isolated from the liver, spleen and thymus at day 16 after tumor inoculation. Two-color staining for CD3 and IL-2R $\beta$ (or NK1.1) was conducted to identify NK cells $\left(\mathrm{CD}^{-}{ }^{-} \mathrm{IL}-2 \mathrm{R} \beta^{+}\right.$or $\left.\mathrm{CD} 3^{-} \mathrm{NK} 1.1^{+}\right)$, NKT cells $\left(\mathrm{CD} 3^{\text {int }} \mathrm{NK} 1.1^{+}\right)$and $\mathrm{T}$ cells $\left(\mathrm{CD} 3^{+} \mathrm{IL}-2 \mathrm{R} \beta^{-}\right.$or $\left.\mathrm{CD} 3^{+} \mathrm{NK} 1.1^{-}\right)$. Two-color staining for CD4 and CD8 was conducted to identify double-positive cells $\left(\mathrm{CD}^{+} \mathrm{CD} 8^{+}\right)$in the thymus. Numbers in the figure represent the percentages of fluorescence-positive cells. The difference is indicated by arrowheads. 
Two-color staining of thymocytes for CD4 and CD8 was also conducted (Figure 4, bottom). The proportion of double-positive $\mathrm{CD}^{+} \mathrm{CD}^{+}$cells prominently decreased in tumor-bearing mice which died. In other words, this pattern showed immunosuppressive states as reported previously. Thymic atrophy $(50 \%)$ was also observed in these mice.

Two-color staining for CD3 and B220 to identify $\mathrm{CD}^{-} \mathrm{B} 220^{+} \mathrm{B}$ cells and such staining for Mac-1 and Gr-1 to identify Mac- $1^{+} \mathrm{Gr}-1^{-}$macrophages and Mac$1^{+} \mathrm{Gr}-1^{+}$granulocytes were then conducted (Figure 5). Lymphocytes were isolated from the liver, spleen and
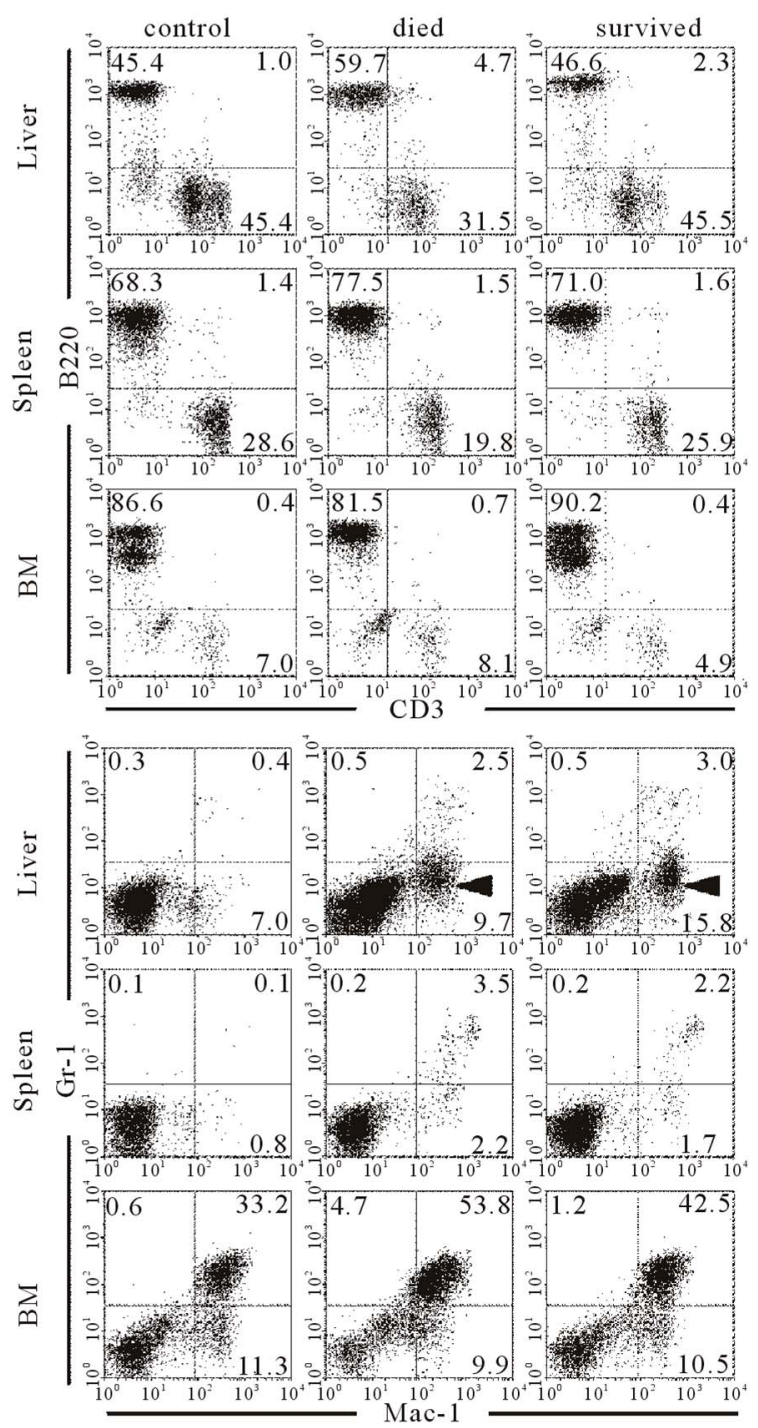

Figure 5. Identification of $B$ cells and macrophages. Mononuclear cells were isolated from the liver, spleen and bone marrow (BM). Two-color staining for CD3 and B220 and that for Mac-1 and Gr-1 was conducted to identify B cells $\left(\mathrm{B} 220^{+} \mathrm{CD}^{-}\right)$and macrophages $\left(\mathrm{Mac}-1^{+} \mathrm{Gr}-1^{-}\right)$. Numbers in the figure represent the percentages of fluorescencepositive cells. The difference is indicated by arrowheads.
$\mathrm{BM}$ on day 16. The proportion of $\mathrm{CD}^{-} \mathrm{B} 220^{+} \mathrm{B}$ cells increased in the liver and spleen of tumor-bearing mice which died. Surviving tumor-bearing mice did not show such change.

The proportion of Mac- $1^{+} \mathrm{Gr}-1^{-}$macrophages tended to increase in the liver of tumor-bearing mice. The proportion of Mac- $1^{+} \mathrm{Gr}-1^{+}$granulocytes tended to slightly increase in the BM of tumor-bearing mice. These changes were seen in both tumor-bearing mice which died and those which survived.

\section{DISCUSSION}

In the present study, we demonstrated that hypothermia appeared consistently in tumor-bearing mice and that these mice finally died of cancer. Such hypothermia was observed around day 16 after EL-4 cell inoculation and at this stage cancer cells grew well. In addition to hypothermia, anemia and immunosuppression were present in tumor-bearing mice. In our recent study in humans [13], cancer patients always suffered from hypothermia, anemia (hypoxia) and immunosuppression. In this regard, it is speculated that a specific internal environment such as hypothermia, anemia and immunosuppression might be required for the maintenance of cancer cell growth.

Several investigators have noticed that cancer cells have few mitochondria in the cytoplasm and produce energy by the glycolysis pathway [14-16]. Recent cumulative evidence also supports this earlier observation [21-25]. On the other hand, normal cells, which divide less (i.e., cardiac cells and red muscle fiber cells), carry many mitochondria and produce energy mainly by the oxidative phosphorylation $[13,26]$. Concerning this, the specific internal environment of hypothermia, anemia and immunosuppression is essential to grow cancer cells in vivo in both animals and humans. Indeed, at the present experimental protocol, $30 \%$ of mice with EL-4 inoculation survived and the inoculated EL-4 cells did not grow well in the peritoneal cavity. None of these mice showed hypothermia, anemia and immunosuppression.

In addition to anemia (hypoxia), hypothermia is important to maintain the glycolysis pathway which supports cell division [13]. Even normal dividing cells such as sperms and skin cells have few mitochondria in the cytoplasm and the optimal temperature is around 32 to $33^{\circ} \mathrm{C}$ (Table 1). For example, the testicles of males descend in the fetal stage. This is to obtain an internal environment of hypothermia for sperm cell division $[27,28]$. It is speculated that tumor cell division may similarly or more strictly require hypothermia.

In our earlier study, we reported that the major effector lymphocyte subsets were invariant NKT cells in mice which were injected with EL-4 lymphoma cells $[17,18]$. 
Table 1. Energy production in body.

\begin{tabular}{lll}
\hline & Glycolysis & Mitochondria \\
\hline Site & cytoplasm & mitochondria \\
Oxygen & - & + \\
Source & glucose & glucose and lipid \\
Temperature & $32^{\circ} \mathrm{C}$ & $>37^{\circ} \mathrm{C}$ \\
Usage & $\begin{array}{l}\text { prompt force } \\
\text { cell division }\end{array}$ & $\begin{array}{l}\text { continuous force } \\
\text { division }\end{array}$ \\
ATP production & quick $(\times 100)$ & slow $(\times 1)$ \\
Efficiency & low $(2$ ATP/glucose $)$ & high $(36$ ATP/glucose $)$ \\
\hline
\end{tabular}

The actual cytotoxicity against EL-4 cells was mediated by such NKT cells. Mice inoculated with EL-4 cells in the present protocol also showed both lymphocytopenia in the blood and a decreased proportion of NKT cells in the liver. These immunosuppression conditions are also speculated to support the growth of EL-4 cells. A similar pattern of lymphocytopenia in the blood has also been seen in almost all cancer patients [13].

There is a question as to why hypothermia and anemia are related to the onset of cancer in humans. We previously proposed the possibility that severe and continuous stress is associated of this phenomenon, namely, severe stress induces hypothermia, hypoxia and hyperglycemia $[29,30]$. Both sympathetic nerve activation and glucocorticoid secretion induce such internal environment. For a short span of life, these internal conditions are beneficial for the stimulation of the glycolysis pathway of energy production $[13,26]$. As a result, prompt force of white muscle fiber increases and person is able to escape from emergency. If stress continues for a long time, however, such condition suppresses oxidative phosphorylation in the mitochondria and results in certain diseased conditions and the onset of cancer. In the present murine model, hyperglycemia was not seen in tumor-bearing mice. However, this result might be an outcome from the leakage of glucose from the urine. This animal model did not contain the onset stage of cancer but only the maintenance of cancer growth. This notion is alternatively possible.

At the last stage of cancer, hypothermia might also be induced by the conditions of cachexia. It was reported that TNF $\alpha$ production is related to the formation of this internal conditions $[31,32]$. In other words, the cause of hypothermia is different between the onset stage and the late stage.

Other changes in the tested parameters include a slight increase in the level of lactate and $\beta$-ketone. Another speculation is that there is an increase of the glycolysis pathway and/or a decrease of the oxidative phosphorylation pathway. In humans, it is known that many cancer patients show acidosis due to the increase of glycolysis $[33,34]$ and some cancer patients show increased levels of ketone bodies [35,36].

\section{CONCLUSION}

It is concluded that hypothermia, anemia (hypoxia) and lymphocytopenia (immunosuppression) are essential for growth of cancer in animals and that they are common signs seen in cancer patients and tumor-bearing mice. These adverse conditions seem to be important for the maintenance of cancer cell growth in vivo. However, a further research including a cancer cell culture experiment under conditions of hypothermia, hypoxia and hyperglycemia is required to support our proposal definitely.

\section{ACKNOWLEDGEMENT}

The authors wish to thank Yuko Kaneko for preparation of the manuscript.

\section{REFERENCES}

[1] Henke M. (2001) Correction of cancer anemia-impact on disease course, prognosis and treatment efficacy, particularly for patients undergoing radiotherapy. Onkologie, 24, 450-454. doi:10.1159/000055125

[2] Rubin H. (2003) Cancer cachexia: its correlations and causes. Proceedings of the National Academy of Sciences of the United States of America, 100, 5384-5389. doi:10.1073/pnas.0931260100

[3] Tanvetyanon T. and Stiff P.J. (2005) Recurrent steroid-responsive pancreatitis associated with myelodysplastic syndrome and transformations. Leukemia and lymphoma, 46, 151-154. doi:10.1080/10428190400011617

[4] Birgegård G., Aapro M.S., Bokemeyer C., Dicato M., Drings P., Hornedo J., Krzakowski M., Ludwig H., Pecorelli S., Schmoll H., Schneider M., Schrijvers D., Shasha D. and Vab Belle S. (2005) Cancer-rela- ted anemia: pathogenesis, prevalence and treatment. Oncology, 68, 3-11. doi:10.1159/000083128

[5] Varlotto J. and Stevenson M.A. (2005) Anemia, tumor hypoxemia, and the cancer patient. International Journal of Radiation Oncology, Biology, Physics, 63, 25-36. doi:10.1016/j.ijrobp.2005.04.049

[6] Al-Waili N.S. (2007) A potential concept in the management of tumors with modulation of prosta- glandin, nitric oxide and antioxidants. Scientific World Journal, 7, 466-478.

[7] Grotto H.Z. (2008) Anemia of cancer: an overview of mechanisms involved in its pathogenesis. Medical Oncology, 25, 12-21. doi:10.1007/s12032-007-9000-8

[8] Lagman R.L., Davis M.P.,. LeGrand S.B and Walsh D. (2005) Common symptoms in advanced cancer. Surgical Clinics of North America, 85, 237-255. doi:10.1016/j.suc.2004.11.004 
[9] Delano M.J. and Moldawer L.L. (2006) The origins of cachexia in acute and chronic inflammatory diseases. Nutrition in Clinical Practice, 21, 68-81. doi:10.1177/011542650602100168

[10] Argilés J.M., Busquets S. and López-Soriano F.J. (2006) Cytokines as mediators and targets for cancer cachexia. Cancer Treatment and Research, 130, 199-217. doi:10.1007/0-387-26283-0_9

[11] Argilés J.M., Busquets S., Moore-Carrasco R., Figueras M., Almendro V. and López-Soriano F.J. (2007) Targets in clinical oncology: the metabolic environment of the patients. Frontiers in Bioscience, 12, 3024-3051.

[12] Lelbach A., Muzes G. and Feher J. (2007) Current perspectives of catabolic mediators of cancer cachexia. Medical Science Monitor, 13, 168-173.

[13] Watanabe M., Miyajima K., Matsui I., Tomiyama-Miyaji C., Kainuma E., Inoue M., Matsumoto H., Kuwano Y. and Abo T. (2010) Internal environment in cancer patients and proposal that carcinogenesis is adaptive response of glycolysis to overcome adverse internal conditions. Health, 2, 781-788. doi:10.4236/health.2010.27118

[14] Dang C.V. and Semenza G.L. (1999) Oncogenic alteration of metabolism. Trends in Biochemical Sciences, 24, 68-72. doi:10.1016/S0968-0004(98)01344-9

[15] Shaw R.J. (2006) Glucose metabolism and cancer. Current Opinion in Cell Biology, 18, 598-608. doi:10.1016/j.ceb.2006.10.005

[16] Warburg O. (1956) On the origin of cancer cells. Science, 123, 309-314. doi:10.1126/science.123.3191.309

[17] Halder R.C., Seki S., Weerasinghe A., Kawamura T., Watanabe H. and Abo T. (1998) Characterization of NK cells and extrathymic T cells generated in the liver of irradiated mice with a liver shield. Clinical and Experimental Immunology, 144, 434-447. doi:10.1046/j.1365-2249.1998.00726.x

[18] Li C., Bai X., Wang S., Tomiyama-Miyaji C., Nagura T., Kawamura T. and Abo T. (2004) Immunopotentiation of NKT cells by low-protein diet and the suppressive effect on tumor metastasis. Cellular Immunology, 231, 96-102. doi:10.1016/j.cellimm.2004.12.005

[19] Ren H.-W., Shen J.-W., Tomiyama-Miyaji C., Watanabe M., Kainuma E., Inoue M., Kuwano Y. and Abo T. (2006) Augmentation of innate immunity by low- dose irradiation. Cellular Immunology, 244, 50-56. doi:10.1016/j.cellimm.2007.02.009

[20] Watanabe H., Miyaji C., Seki S. and Abo T. (1996) C-kit ${ }^{+}$ stem cells and thymocyte precursors in the livers of adult mice. Journal of Experimental medicine, 184, 687-693. doi:10.1084/jem.184.2.687

[21] Kondoh H. (2008) Cellular life span and the Warburg effect. Experimental Cell Research, 314, 1923-1928.

[22] Nijsten M.W.N. and van Dam G.M. (2009) Hypothesis: using the Warburg effect against cancer by reducing glucose and providing lactate. Medical Hypotheses, 73, 48-51. doi:10.1016/j.mehy.2009.01.041

[23] Heiden M.G.V., Cantley L.C. and Thompson C.B. (2009) Understanding the Warburg effect: the metabolic re- quirements of cell proliferation. Science, 324, 1029-1033. doi:10.1126/science.1160809

[24] Máximo V., Lima J., Soares P., Sobrinho- Simões M. (2009) Mitochondria and cancer. Virchows Archiv, 454, 481-495.

[25] Lee H.-C. and Wei Y.-H. (2009) Mitochondria DNA instability and metabolic shift in human cancers. International Journal of Molecular Sciences. 10, 674-701. doi:10.3390/ijms10020674

[26] Kainuma E., Watanabe M., Tomiyama-Miyaji C., Inoue M., Kuwano Y., Ren H.-W. and Abo T. (2009) Proposal of alternative mechanism responsible for the function of high-speed swimsuits. Biomedical Research, 30, 69-70. doi:10.2220/biomedres.30.69

[27] Zorgniotti A.W. and Sealfon A.I. (1984) Scrotal hypothermia: new therapy for poor semen. Urology, 23, 439-441. doi:10.1016/S0090-4295(84)80006-0

[28] Davis J.R. and Horowitz A.M. (1979) Response of the rabbit isolated testicular capsule at hypothermic and hyperthermic temperatures to norepinephrine, acetylcholine and prostaglandin F2 alpha. Andrologia, 11, 453-460.

[29] Watanabe M., Tomiyama-Miyaji C., Kainuma E., Inoue M., Kuwano Y., Ren H.-W., Shen J.-W. and Abo T. (2008) Role of $\alpha$-adrenergic stimulus in stress-induced modulation of body temperature, blood glucose and innate immunity. Immunology Letters, 115, 43-49. doi:10.1016/j.imlet.2007.09.010

[30] Kainuma E., Watanabe M., Tomiyama-Miyaji C., Inoue M., Kuwano Y., Ren H.-W. and Abo T. (2009) Association of glucocorticoid with stress-induced modulation of body temperature, blood glucose and innate immunity. Psychoneuroendocrinology, 34, 1459-1468. doi:10.1016/j.psyneuen.2009.04.021

[31] Smith B.K., Conn C.A. and Kluger M.J. (1993) Experimental cachexia: effects of MCA sarcoma in the Fischer rat. American Journal of Physiology, 265, R376-384.

[32] Smith B.K. and Kluger M.J. (1993) Anti-TNF-alpha antibodies normalized body temperature and enhanced food intake in tumor-bearing rats. American Journal of Physiology, 265, R615-619.

[33] DeClerck K. and Elble R.C. (2010) The role of hypoxia and acidosis in promoting metastasis and resistance to chemotherapy. Frontiers in Bioscience, 15, 213-225. doi: $10.2741 / 3616$

[34] Chiche J., Brahimi-Horn M.C. and Pouysségur J. (2010) Tumour hypoxia induces a metabolic shift causing acidosis: a common feature in cancer. Journal of Cellular and Molecular Medicine, 14, 771-794. doi:10.1111/j.1582-4934.2009.00994.x

[35] Lin M.V., Bishop G. and Benito-Herrero M. (2010) Diabetic ketoacidosis in type 2 diabetics: a novel presentation of pancreatic adenocarcinoma. Journal of General Internal Medicine, 25, 369-373.

[36] Jobe B.A., Bierman M.H. and Mezzacappa F.J (1993) Hyperglycemia as a paraneoplastic endocrinopathy in renal cell carcinoma: a case report and review of the literature. Nebraska Medical Journal, 78, 349-351. 